\title{
Phosphate homeostasis in Bartter syndrome: a case-control study
}

\author{
Alberto Bettinelli - Cristina Viganò • Maria Cristina Provero • Francesco Barretta • \\ Alessandra Albisetti • Silvana Tedeschi • Barbara Scicchitano • Mario G. Bianchetti
}

Received: 13 October 2013 / Revised: 24 April 2014 / Accepted: 29 April 2014 / Published online: 6 June 2014

(C) IPNA 2014

\begin{abstract}
Background Bartter patients may be hypercalciuric. Additional abnormalities in the metabolism of calcium, phosphate, and calciotropic hormones have occasionally been reported.

Methods The metabolism of calcium, phosphate, and calciotropic hormones was investigated in 15 patients with Bartter syndrome and 15 healthy subjects.

Results Compared to the controls, Bartter patients had significantly reduced plasma phosphate \{mean [interquartile range]:1.29 [1.16-1.46] vs. $1.61[1.54-1.67] \mathrm{mmol} / \mathrm{L}\}$ and maximal tubular phosphate reabsorption (1.16 [1.00-1.35] vs. $1.41[1.37-1.47] \mathrm{mmol} / \mathrm{L})$ and significantly increased parathyroid hormone (PTH) level (6.1 [4.5-7.7] vs. 2.8 [2.2-4.4] pmol/L). However, patients and controls did not differ in blood calcium, 25-hydroxyvitamin $\mathrm{D}$, alkaline phosphatase, and osteocalcin levels. In patients, an inverse correlation $(P<0.05)$ was noted between total plasma calcium or glomerular filtration rate and PTH concentration. A positive correlation was also noted between PTH and osteocalcin
\end{abstract}

\footnotetext{
A. Bettinelli $\cdot$ M. C. Provero $\cdot$ B. Scicchitano

Division of Pediatrics, San Leopoldo Mandic Hospital, Merate,

Lecco, Italy

C. Viganò

Division of Orthopedics, San Leopoldo Mandic Hospital, Merate,

Lecco, Italy

\section{C. Provero}

Department of Clinical and Experimental Medicine, Ospedale

Pediatrico Filippo del Ponte, Varese, Italy

F. Barretta

Department of Clinical Sciences and Community Health, University

of Milan and Epidemiology Unit, Milan, Italy

F. Barretta

Department of Preventive Medicine, Foundation IRCCS Cà Granda

Ospedale Maggiore Policlinico, Milan, Italy
}

concentrations $(P<0.005)$, as well as between chloriduria or natriuria and phosphaturia $(P<0.001)$. No correlation was noted between calciuria and $\mathrm{PTH}$ concentration or between urinary or circulating phosphate and $\mathrm{PTH}$.

Conclusions The results of this study demonstrate a tendency towards renal phosphate wasting and elevated circulating PTH levels in Bartter patients.

Keywords Bartter syndrome · Calcium . Hypophosphatemia $\cdot$ Maximal tubular reabsorption of phosphate $\cdot$ Parathyroid hormone

\section{Introduction}

Bartter syndrome is a group of very similar recessive tubulopathies with a unifying pathophysiology consisting of postproximal salt loss [1]. Affected patients present with

\author{
A. Albisetti \\ Department of Clinical Orthopedics and Rehabilitation, University of \\ Milan, Milan, Italy \\ S. Tedeschi \\ Laboratory of Medical Genetics, Foundation IRCCS Ca' Granda \\ Ospedale Maggiore Policlinico, Milan, Italy
}

M. G. Bianchetti

Integrated Department of Pediatrics, Ente Ospedaliero Cantonale Ticinese, University of Berne, Berne, Switzerland

M. G. Bianchetti $(\triangle)$

San Giovanni Hospital, 6500 Bellinzona, Switzerland

e-mail: mario.bianchetti@pediatrician.ch 
normal or low blood pressure, hypokalemia, hyperreninemia, and a tendency towards nephrocalcinosis and hypercalciuria in the neonatal variant [1]. Further abnormalities in the metabolism of calcium, inorganic phosphate, and calciotropic hormones have sometimes been noted in these disorders, although data characterizing the levels of classic calciotropic hormones during the stable phases of the condition are sparse $[2,3]$.

Here we present the results of our study in which we investigated the metabolism of calcium, inorganic phosphate, and classic calciotropic hormones in patients affected with Bartter syndrome.

\section{Patients and methods}

Participants eligible for entry into the study were all Bartter patients on regular follow-up at the renal unit of the Division of Pediatrics, San Leopoldo Mandic Hospital, Merate (Italy). Fifteen patients from 14 different families ( 8 females and 7 males, median age 7.3 years, age range $3.2-18$ ) who presented for a scheduled visit between September and November 2012 were ultimately enrolled in the study. These patients had a history of polyhydramnios $(N=13)$, premature birth $(N=13)$, or ultrasound findings consistent with nephrocalcinosis $(N=13)$ (Table 1). A control group of 15 healthy subjects ( 8 females and 7 males median age 11 years, age range 6.9-18 years) was also studied.
The study design was approved by the Human Subjects Research Committee of Merate-Lecco Hospital.

The diagnosis of Bartter syndrome was based on the presence of normal or low blood pressure, hypokalemia, inappropriately high urinary excretion of chloride, and hyperreninemia. A molecular evaluation of the SLC12A1, KCNJ1, CLCNKB, and $B S N D$ genes had been performed on the 15 patients, according to standard procedure $[4,5]$. The Bartter patients, who did not discontinue their respective medication with potassium chloride $(N=15)$, the inhibitor of prostaglandin synthesis indomethacin $(N=14)$, and the potassium-sparing diuretic spironolactone $(N=3)$, and the control subjects attended the outpatient clinic after overnight fasting and received a tap water load of $400 \mathrm{~mL}$ [6]. After voiding the bladder, an approximately 2-h urine specimen was collected and a mid-point blood sample was collected [6]. Creatinine, sodium, chloride, potassium, total calcium and magnesium, and inorganic phosphate were assessed in both the blood and urine; urea, bicarbonate, albumin, 25-hydroxyvitamin D, alkaline phosphatase, intact parathyroid hormone (PTH), and osteocalcin were assessed in the blood only. Creatinine, urea, sodium, bicarbonate, chloride, potassium, albumin, total calcium and magnesium, and inorganic phosphate were measured on an automated auto-analyzer using colorimetric assays or ion-selective electrodes. Intact PTH was measured by a two-site radioimmunometric assay, 25-hydroxyvitamin D was measured using a competitive

Table 1 Mutations and main clinical prenatal and neonatal data in 15 patients with Bartter syndromes

\begin{tabular}{|c|c|c|c|c|c|}
\hline Patient number ${ }^{\mathrm{a}}$ & Gene $^{b}$ & Nucleotide changes ${ }^{c}$ & Polyhydramnios & Gestational age (weeks) & Nephrocalcinosis \\
\hline 1 & SLC12A1 & c. $[730 \mathrm{insG}] ;[1432 \mathrm{G}>\mathrm{A}]$ & Yes & 30 & Yes \\
\hline 2 & & c. $\left[903 \_904 \mathrm{delC}\right] ;[$ [1493C $>\mathrm{T}]$ & Yes & 36 & Yes \\
\hline 3 & & c. $[572 \mathrm{~T}>\mathrm{A}] ;[1493 \mathrm{C}>\mathrm{T}]$ & Yes & 28 & Yes \\
\hline 4 & & c.[1567delT]; [?] & Yes & 35 & Yes \\
\hline 5 & & c. $[366 \mathrm{G}>\mathrm{A}] ;[1973 \mathrm{G}>\mathrm{A}]$ & Yes & 34 & Yes \\
\hline 6 & & c. $[570 \mathrm{~T}>\mathrm{A}] ;[630 \mathrm{~T}>\mathrm{C}]$ & Yes & 31 & Yes \\
\hline $7^{\mathrm{d}}$ & KCNJ1 & c. $[629 \mathrm{C}>\mathrm{T}] ;[629 \mathrm{C}>\mathrm{T}]$ & Yes & 32 & Yes \\
\hline $8^{\mathrm{d}}$ & & c. $[629 \mathrm{C}>\mathrm{T}] ;[629 \mathrm{C}>\mathrm{T}]$ & Yes & 37 & Yes \\
\hline 9 & CLCNKB & c.[850_855 dupT]; [1-?_2064+?del] & No & 40 & Yes \\
\hline 10 & & c. $[725 \mathrm{C}>\mathbf{A}] ;[1 ? .2064+? \mathrm{del}]$ & Yes & 39 & No \\
\hline 11 & & c. $[206 \mathrm{C}>\mathrm{A}] ;[480 \mathrm{~T}>\mathrm{A}]$ & No & 40 & No \\
\hline 12 & $B S N D$ & c. $[3 \mathrm{G}>\mathrm{A}] ;[3 \mathrm{G}>\mathrm{A}]$ & Yes & 39 & Yes \\
\hline 13 & Not detected & & Yes & 39 & Yes \\
\hline 14 & & & Yes & 33 & Yes \\
\hline 15 & & & Yes & 38 & Yes \\
\hline
\end{tabular}

${ }^{\text {a }}$ Patients $1-8$ and patients 14 and 15 were classified clinically as loop disorder Bartter syndrome; patients 9-11 and 13 were classified as distal convoluted tubule disorder Bartter syndrome; patient 12 was classified as combined disorder Bartter syndrome

${ }^{\mathrm{b}}$ Mutations of the $S L C 12 A 1, K C N J 1, C L C N K B$, and $B S N D$ genes were detected in 12 of the 15 patients. GenBank accession numbers as reference sequences: $S L C 12 A 3=\mathrm{NM}$ 000339.2; SLC12A1=NM_000338.2; KCNJ1=NM_000220.3; CLCNKB=NM_000085.4. Nomenclature according to Human Genomic Variant Society

${ }^{\mathrm{c}}$ Novel mutations are given in bold font

${ }^{\mathrm{d}}$ These patients are first-degree cousins 
protein-binding assay, and osteocalcin was measured by radioimmunoassay, as previously reported [6].

The glomerular filtration rate (GFR) was estimated from height measurements and plasma creatinine levels [7]. Standard equations were used to calculate the fractional urinary excretion of sodium, chloride, potassium, calcium, magnesium, and inorganic phosphate and the maximal tubular reabsorption of inorganic phosphate, which is the best means of defining the renal tubular handling of this ion $[8,9]$. Albumincorrected plasma calcium was calculated as follows: for every gram/liter by which plasma albumin exceeds $40 \mathrm{~g} / \mathrm{L}, 0.025$ is subtracted from the total calcium measurement, with the reverse procedure for albumin values of $<40 \mathrm{~g} / \mathrm{L}$. Blood and urinary levels of sodium, chloride, potassium, and magnesium are age- and gender-independent [10], but blood levels of inorganic phosphate and those of its maximal tubular reabsorption vary significantly with age and gender $[8,9]$. Hence, the values obtained in our study were also compared with those given in the literature $[8,9]$ and expressed as the standard deviation score (SDS).
Table 2 Laboratory findings in the 15 patients affected with Bartter syndrome and in the 15 control subjects ${ }^{\mathrm{a}}$
Values are presented as the median with the interquartile range (IQR) given in square brackets

SDS, Standard deviation score; NS, not significant; PTH, parathyroid hormone

${ }^{\text {a }}$ Patients affected with Bartter syndrome: $N=15 ; 8$ females, 7 males; median age 7.3 years; age range $3.2-18.0$ years. Control subjects: $N=15 ; 7$ females, 8 males; median age 11.1 years; age range 6.9-17.8 years

${ }^{\mathrm{b}}$ Glomerular filtration rate was $\geq 85 \mathrm{~mL} /\left(\min .1 .73 \mathrm{~m}^{2}\right)$ in 14 of the 15 patients

\begin{tabular}{|c|c|c|c|}
\hline Laboratory findings & $\begin{array}{l}\text { Patients with Bartter } \\
\text { syndrome }\end{array}$ & $\begin{array}{l}\text { Control } \\
\text { subjects }\end{array}$ & $\begin{array}{l}\text { Significance } \\
(P \text { value })\end{array}$ \\
\hline \multicolumn{4}{|l|}{ Body height (m) } \\
\hline Absolute value & $1.17[1.02-1.50]$ & $1.49[1.40-1.54]$ & $<0.01$ \\
\hline SDS & $-1.6[-0.9$ to -2.3$]$ & $0.3[-0.3$ to 0.8$]$ & $<0.01$ \\
\hline \multicolumn{4}{|l|}{ Body weight (kg) } \\
\hline Absolute value & $19.7[15.3-37.5]$ & $42.5[37.0-49.5]$ & $<0.03$ \\
\hline SDS & $-1.6[-1.0$ to -2.8$]$ & $0.4[-0.3$ to 0.8$]$ & $<0.01$ \\
\hline Marshall-Tanner puberty stage & $2[1-5]$ & $2[1-5]$ & NS \\
\hline Plasma creatinine $(\mu \mathrm{mol} / \mathrm{L})$ & $53[35-66]$ & $55[50-57]$ & NS \\
\hline $\begin{array}{l}\text { Glomerular filtration rate } \\
{\left[\mathrm{mL} /\left(\min .1 .73 \mathrm{~m}^{2}\right)\right]}\end{array}$ & $135[125-144]^{\mathrm{b}}$ & $132[126-138]$ & NS \\
\hline Plasma urea $(\mathrm{mmol} / \mathrm{L})$ & $4.3[4.2-7.2]$ & $5.8[4.5-6.0]$ & NS \\
\hline \multicolumn{4}{|l|}{ Sodium } \\
\hline Plasma level (mmol/L) & 137 [136-138] & $136[135-137]$ & NS \\
\hline Fractional excretion, $10^{-2}$ & $0.43[0.27-1.34]$ & $0.50[0.30-0.61]$ & NS \\
\hline Plasma bicarbonate $(\mathrm{mmol} / \mathrm{L})$ & $27[26-28]$ & $27[26-28]$ & NS \\
\hline \multicolumn{4}{|l|}{ Chloride } \\
\hline Plasma level (mmol/L) & 100 [99-102] & $101[100-102]$ & NS \\
\hline Fractional excretion, $10^{-2}$ & $1.05[0.66-2.10]$ & $0.60[0.4-0.75]$ & $<0.001$ \\
\hline \multicolumn{4}{|l|}{ Potassium } \\
\hline Plasma level (mmol/L) & $3.3[3.0-3.6]$ & $4.0[3.9-4.3]$ & $<0.001$ \\
\hline Fractional excretion, $10^{-2}$ & $13.9[11.6-44.9]$ & $5.3[3.1-9.2]$ & $<0.005$ \\
\hline \multicolumn{4}{|l|}{ Magnesium } \\
\hline Plasma level (mmol/L) & $0.90[0.80-1.00]$ & $0.91[0.79-0.94]$ & NS \\
\hline Fractional excretion, $10^{-2}$ & $4.27[2.70-4.60]$ & $3.20[2.65-4.08]$ & NS \\
\hline \multicolumn{4}{|l|}{ Calcium } \\
\hline Total plasma level (mmol/L) & $2.36[2.35-2.42]$ & $2.41[2.38-2.45]$ & NS \\
\hline Albumin corrected level (mmol/L) & $2.37[2.34-2.44]$ & $2.41[2.36-2.46]$ & NS \\
\hline Fractional excretion, $10^{-2}$ & $1.77[1.17-2.63]$ & $0.81[0.63-1.11]$ & $<0.05$ \\
\hline \multicolumn{4}{|l|}{ Inorganic phosphate } \\
\hline Plasma level (mmol/L) & $1.29[1.16-1.46]$ & $1.61[1.54-1.67]$ & $<0.01$ \\
\hline Plasma level SDS & $-0.5[-1.3$ to 0.1$]$ & $1.0[0.4-1.3]$ & $<0.01$ \\
\hline Fractional excretion, $10^{-2}$ & $9.0[5.8-14.4]$ & $11.4[10.0-13.0]$ & NS \\
\hline Maximal tubular reabsorption $(\mathrm{mmol} / \mathrm{L})$ & $1.16[1.00-1.35]$ & $1.41[1.37-1.47]$ & $<0.01$ \\
\hline Maximal tubular reabsorption SDS & $-0.7[-1.6$ to 0.3$]$ & $0.5[0.3-1.0]$ & $<0.01$ \\
\hline Serum 25-hydroxyvitamin D (mmol/L) & $48[35-60]$ & $44[33-48]$ & NS \\
\hline Plasma alkaline phosphatase (U/L) & 244 [208-304] & $256[194-324]$ & NS \\
\hline Serum intact PTH $(\mathrm{pmol} / \mathrm{L})$ & $6.1[4.5-7.7]$ & $2.8[2.2-4.4]$ & $<0.001$ \\
\hline Serum osteocalcin $(\mu \mathrm{g} / \mathrm{L})$ & $59.2[38.1-90.4]$ & $66.4[48.0-103.0]$ & NS \\
\hline
\end{tabular}


Fig. 1 Total plasma calcium and inorganic phosphate levels, fractional calcium excretion, maximal tubular reabsorption of inorganic phosphate, and serum intact parathyroid hormone and 25-hydroxyvitamin D levels in 15 Bartter syndrome patients and in 15 control subjects. Differently colored filled circles denote patients with mutations affecting either the $S L C 12 A 1$ or the $K C N J 1$ gene (type $I-I I$ ), patients with mutations affecting the $C L C N K$ gene (type $I I I$ ) patients with mutations affecting the $B S N D$ (Barttin), and patients without any mutation, as well as the control subjects. NS Not significant. See text and Table 2 for a detailed description of the two study groups
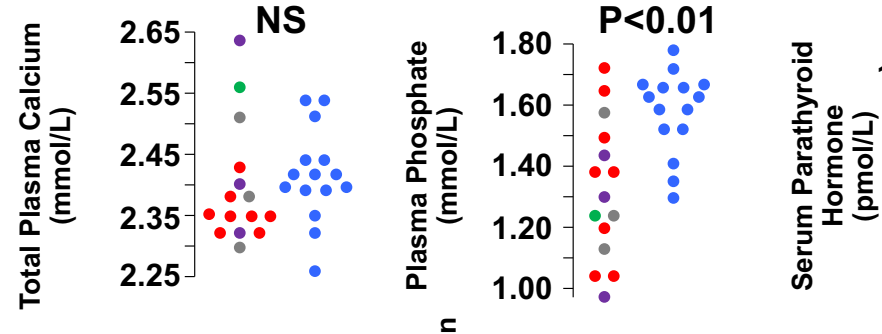

$P<0.01$
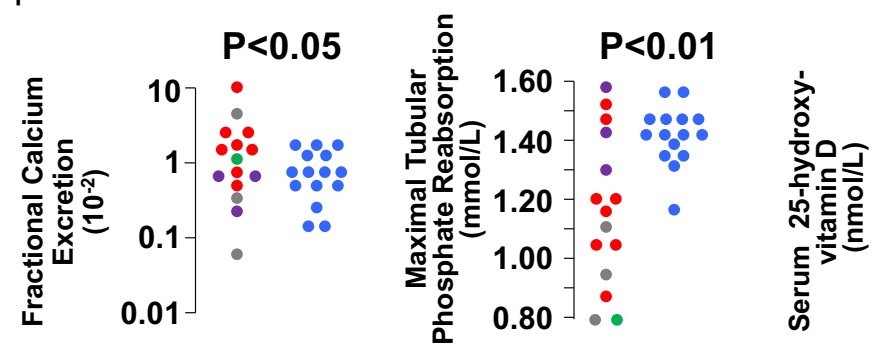

0.0

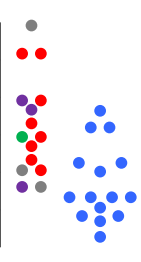

NS

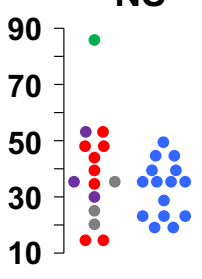

Descriptive statistics are presented as the median and interquartile range (25th to 75 th percentile and includes half of the data points). Two-tailed Wilcoxon-Mann-Whitney tests for independent samples and linear regressions with the rank correlation coefficient $r_{\mathrm{s}}$ were performed for the analysis. Significance was assumed when $P<0.05$.

\section{Results}

Molecular biology

Genetic analysis revealed mutations in 12 of the 15 patients enrolled in the study, with three patients having a homozygous mutation, eight having a compound heterozygous mutation, and one having a single heterozygous mutation (Table 1). One of these patients has been previously diagnosed as Bartter syndrome type IV based on the presence of a sensorineural hearing loss [11]. Ten mutations had been previously described, whereas seven mutations (4 missense and 1 frameshift in the SLC12A1 gene and 1 missense and 1 frameshift in the $C L C N K B$ gene) are novel. All of the new variants were considered to be pathogenetic - the two frameshift mutations because they lead to truncated protein synthesis, and the missense mutations because all are on conserved residues and were not detected in 100 healthy chromosomes or found in the Exome Variant Server database. Molecular analysis did not detect any mutation in three patients.

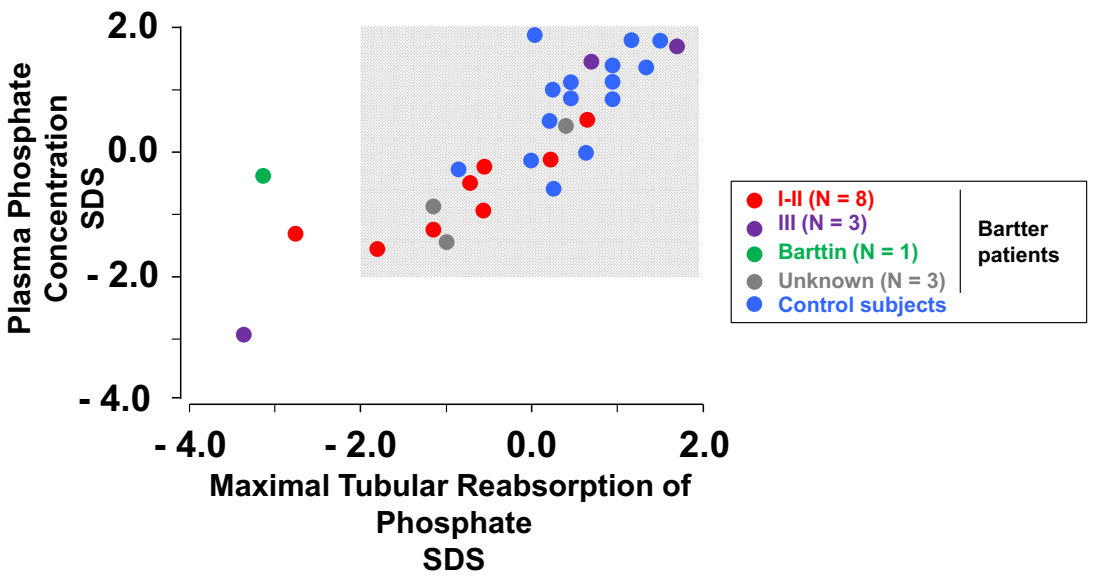

Fig. 2 Relationship between maximal tubular reabsorption of inorganic phosphate and corresponding plasma phosphate level in 15 Bartter syndrome patients and 15 control subjects. The results are expressed as standard deviation score (SDS). Shaded area Reference values obtained from the literature. Differently colored filled circles denote patients with mutations affecting either the $S L C 12 A 1$ or the $K C N J 1$ gene (type $I-I I$ ), patients with mutations affecting the $C L C N K$ gene (type $I I I)$ patients with mutations affecting the $B S N D$ (Barttin), and patients without any mutation, as well as the control subjects 
Table 3 Significant regressions in 15 patients with Bartter syndrome

\begin{tabular}{|c|c|c|c|c|c|}
\hline Independent value & Dependent value & Slope & Intercept & $\begin{array}{l}\text { Correlation } \\
\text { coefficient }\left(r_{\mathrm{s}}\right)\end{array}$ & Significance $(P)$ \\
\hline Total calcium level & Intact PTH & -146.1 & 414 & -0.529 & $<0.05$ \\
\hline Glomerular filtration rate & Intact PTH & -0.277 & 98.9 & -0.521 & $<0.05$ \\
\hline Intact parathyroid hormone & Osteocalcin & 0.974 & 0.439 & 0.800 & $<0.005$ \\
\hline Fraction chloride excretion & Fractional phosphate excretion & 2.90 & 5.76 & 0.822 & $<0.001$ \\
\hline Fractional sodium excretion & Fractional phosphate excretion & 7.54 & 5.24 & 0.814 & $<0.001$ \\
\hline
\end{tabular}

PTH parathyroid hormone

\section{Clinical and biochemical data}

Growth and laboratory findings are shown in Table 2 and Fig. 1. Body height, height SDS, weight and weight SDS were significantly lower in the group of patients affected with Bartter syndrome than in the control group. Patients affected with Bartter syndrome and control subjects did not significantly differ with respect to puberty stage, plasma creatinine and urea, estimated GFR, plasma bicarbonate and chloride, and plasma and urinary sodium and magnesium. As expected, hypokalemia, hyperkaliuria, hyperchloriduria, and hypercalciuria were noted in Bartter patients. Plasma inorganic phosphate level $(P<0.01)$ and maximal tubular phosphate reabsorption were significantly reduced $(P<0.01)$ and serum intact PTH level significantly increased $(P<0.01)$ in Bartter patients as compared with control subjects. However, patients and controls did not significantly differ with respect to total calcium blood level, serum 25-hydroxyvitamin D, plasma alkaline phosphatase and serum osteocalcin. PTH level was $>10$ $\mathrm{pmol} / \mathrm{L}$ in three patients, with only one of these three patients having a mildly reduced GFR of $58 \mathrm{~mL} /\left(\min .1 .73 \mathrm{~m}^{2}\right)$. Figure 2 shows the relationship between the maximal tubular reabsorption of phosphate and its plasma level in Bartter patients and healthy controls, which are compared with age- and sex-specific reference values from the literature $[4,5]$. The maximal tubular reabsorption of phosphate was low in three patients, and circulating phosphate level was low in one patient.

In Bartter patients we noted a significant inverse correlation $(P<0.05)$ between total plasma calcium or GFR, taken as the independent value, and PTH, taken as the dependent value (Table 3). Finally, a significant positive correlation was noted between PTH and osteocalcin $(P<0.005)$ and between urinary chloride or sodium and urinary phosphate $(P<0.001)$. On the contrary, no significant correlation was noted between urinary calcium and $\mathrm{PTH}$, between urinary or circulating phosphate and $\mathrm{PTH}$, and between maximal tubular reabsorption of phosphate and PTH.

\section{Discussion}

The clinical and laboratory characteristics of Bartter syndrome may be mimicked among others by treatment with loop diuretics [1]. These natriuretic agents directly increase urinary phosphate excretion in the presence of a normal extracellular fluid volume [12]. On the other hand, there is no phosphaturia in the presence of a contracted extracellular fluid volume, i.e., when urinary salt losses are not replaced [12]. Our casecontrol study was performed in biochemically and genetically characterized Bartter patients. In these unselected patients, who were on long-term management with potassium chloride, indomethacin and, more rarely, spironolactone, we determined hypercalciuria, renal phosphate wasting, and elevated circulating PTH levels.

The molecular biology studies performed in our patients also disclosed seven previously unreported mutations in either the $S L C 12 A 1$ or $C L C N K B$ genes.

To our knowledge, the metabolism of calcium, inorganic phosphate, and PTH in Bartter patients has only been

Table 4 Data on blood calcium, inorganic phosphate, and parathyroid hormone levels and on urinary phosphate excretion in patients affected with Bartter syndromes

\begin{tabular}{|c|c|c|c|c|c|}
\hline \multirow[t]{2}{*}{ Reference } & \multirow{2}{*}{$\begin{array}{l}\text { Glomerular filtration rate } \\
{\left[\mathrm{mL} /\left(\min .1 .73 \mathrm{~m}^{2}\right)\right]}\end{array}$} & \multicolumn{3}{|c|}{ Blood level (mmol/L) } & \multirow{2}{*}{$\begin{array}{l}\text { Urinary phosphate } \\
\text { excretion }\end{array}$} \\
\hline & & PTH & Calcium & Phosphate & \\
\hline Leonhardt et al. [2] & Reduced & Elevated & Low & Elevated & Normal \\
\hline Rodríguez-Soriano et al. [3] & Normal & Normal & Normal-high & Low & Not assessed \\
\hline Present study & Normal & Elevated & Normal & Low & Elevated \\
\hline
\end{tabular}

PTH parathyroid hormone 
addressed in our study and in two earlier studies [2, 3], although the latter two studies did not include a well-defined pediatric control group (Table 4). The tendency towards elevated PTH levels and hyperphosphatemia noted in German patients in the study of Leonhardt et al. [2] is likely the consequence of a mildly reduced GFR. As in our patients, a tendency towards hypophosphatemia was noted in Spanish pediatric patients, reported by Rodríguez-Soriano et al. [3], with a normal GFR (phosphaturia was not measured in these patients). However, contrary to our patients, in the Spanish patients, the PTH level was normal and the circulating calcium level was slightly elevated. As in our patients, hypophosphatemia and hyperparathyroidism were also noted in an adolescent case of Bartter syndrome reported 35 years ago [13].

The mechanisms underlying renal phosphate wasting and hypophosphatemia in Bartter patients remain elusive. Bartter patients tend to be alkalotic; it is recognized, however, that metabolic alkalosis, contrary to respiratory alkalosis, does not noticeably modify phosphate metabolism [14-16]. There is some phosphate wasting in primary hyperparathyroidism, but no correlation was noted between urinary or circulating phosphate and PTH in our Bartter patients [17]. Prostaglandin overproduction, a constant finding in Bartter syndrome, might underlie hyperphosphaturia in our patients [14-16]. This assumption is supported by the observation that circulating phosphate levels increase in patients with Barter syndromes who are being treated with inhibitors of prostaglandin synthesis [2]. When we take into account that our Bartter patients were on treatment with indomethacin, an effective inhibitor of prostaglandin synthesis, we can assume that factors other than hyperprostaglandinism mainly account for renal phosphate wasting. We feel that the mild tendency to renal phosphate wasting observed in our Bartter patients results from a phosphaturic effect associated with the renal tubular dysfunction, which is in part counterbalanced by existing extracellular fluid volume contraction [12]. This impression is supported by the significant correlation between urinary chloride or sodium and urinary phosphate.

There are a number of limitations to our study. First, we included Bartter patients with both prenatal and classic presentation. Second, only a few patients $(N=15)$ were studied. Third, we did not measure urinary prostaglandin excretion and phosphaturic hormone fibroblast growth factor level [15].

In conclusion, this case-control study demonstrates the existence of a tendency towards elevated circulating PTH levels and renal phosphate wasting in Bartter patients with normal GFR. A multicenter study with a large number of patients and the determination of prostaglandinuria, reninemia, fibroblast growth factor 23 , and 1,25dihydroxyvitamin $\mathrm{D}$ should be helpful in establishing the mechanisms underlying these biochemical abnormalities.

\section{Conflict of interest None.}

\section{References}

1. Seyberth HW, Schlingmann KP (2011) Bartter- and Gitelman-like syndromes: salt-losing tubulopathies with loop or DCT defects. Pediatr Nephrol 26:1789-1802

2. Leonhardt A, Timmersmanns G, Roth B, Seyberth HV (1992) Calcium homeostasis and hypercalciuria in hyperprostaglandin $\mathrm{E}$ syndrome. J Pediatr 120:546-554

3. Rodríguez-Soriano J, Vallo A, Aguirre M (2005) Bone mineral density and bone turnover in patients with Bartter syndrome. Pediatr Nephrol 20:1120-1125

4. Bettinelli A, Borsa N, Bellantuono R, Syrèn ML, Calabrese R, Edefonti A, Komninos J, Santostefano M, Beccaria L, Pela I, Bianchetti MG, Tedeschi S (2007) Patients with biallelic mutations in the chloride channel gene CLCNKB: long-term management and outcome. Am J Kidney Dis 49:91-98

5. Puricelli E, Bettinelli A, Borsa N, Sironi F, Mattiello C, Tammaro F, Tedeschi S, Bianchetti MG, Italian Collaborative Group for Bartter Syndrome (2010) Long-term follow-up of patients with Bartter syndrome type I and II. Nephrol Dial Transplant 25:2976-2981

6. Viganò C, Amoruso C, Barretta F, Minnici G, Albisetti W, Syrèn ML, Bianchetti MG, Bettinelli A (2013) Renal phosphate handling in Gitelman syndrome - the results of a case-control study. Pediatr Nephrol 28:65-70

7. Schwartz GJ, Work DF (2009) Measurement and estimation of GFR in children and adolescents. Clin J Am Soc Nephrol 4:1832-1843

8. Brodehl J, Gellissen K, Weber HP (1982) Postnatal development of tubular phosphate reabsorption. Clin Nephrol 17:163-171

9. Brodehl J (1994) Assessment and interpretation of the tubular threshold for phosphate in infants and children. Pediatr Nephrol 8:645

10. Burritt MF, Slockbower JM, Forsman RW, Offord KP, Bergstralh EJ, Smithson WA (1990) Pediatric reference intervals for 19 biologic variables in healthy children. Mayo Clin Proc 65:329-336

11. Zaffanello M, Taranta A, Palma A, Bettinelli A, Marseglia GL, Emma F (2006) Type IV Bartter syndrome: report of two new cases. Pediatr Nephrol 21:766-770

12. Greger R, Wangemann P (1987) Loop diuretics. Ren Physiol 10:174-183

13. Sann L, David L, Bernheim J, François R (1978) Hypophosphatemia and hyperparathyroidism in a case of Bartter's syndrome. Helv Paediatr Acta 33:299-310

14. Lang F, Greger R, Knox FG, Oberleithner H (1981) Factors modulating the renal handling of phosphate. Ren Physiol 4:1-16

15. Friedlander G (1996) Regulation of renal phosphate handling: recent findings. Curr Opin Nephrol Hypertens 5:316-320

16. Hu MC, Shiizaki K, Kuro-o M, Moe OW (2013) Fibroblast growth factor 23 and Klotho: physiology and pathophysiology of an endocrine network of mineral metabolism. Annu Rev Physiol 75:503-533

17. Bilezikian JP (2012) Primary hyperparathyroidism. Endocr Pract 18: 781-790 